\title{
When narratives become argumentation
}

\author{
EVA CHRISTENSEN
}

Narratives and storytelling have been closely examined by sociolinguists, historians and psychologists in recent years. Theoretical approaches such as "small story research" as well as Conversational Analysis have thoroughly described the function and organization of narratives, and demonstrated how speakers in interaction negotiate and coconstruct narratives and stories through social interaction. But what happens when the story ends? How does the sense-making among social speakers continue? And how are the stories retold, re-used and reinterpreted?

This article examines discussions from a focus group interview where speakers include past events strategically in their argumentation. Six men living at Christiania, the "free town" within Copenhagen, discuss current problems and how to solve them. During their talk they refer to past episodes and events. The analysis focuses on connections between argumentation and narrative, asking:

1. How do the participants employ past events in their talk to achieve strategic and argumentative goals? and 2. How do the dynamics of and argumentation in the talk shape the interactional understanding of the past? 